\title{
Papillary mesothelioma of peritoneum involving fallopian tube: A challenging case
}

\author{
Asim Quershi ${ }^{1}$, Vaidyanathan Gowri*2, Ikram Burney ${ }^{3}$, Moza Kalbani ${ }^{2}$ \\ ${ }^{1}$ Department of Pathology, Sultan Qaboos University Hospital, Muscat, Oman \\ ${ }^{2}$ Department of Obstetrics \& Gynecology, Sultan Qaboos University Hospital, Muscat, Oman \\ ${ }^{3}$ Department of Medicine, Sultan Qaboos University Hospital, Muscat, Oman
}

Received: September 12, 2016

DOI: $10.5430 /$ jst.v7n1p20
Accepted: November 13, 2016 Online Published: December 5, 2016

URL: http://dx.doi.org/10.5430/jst.v7n1p20

\begin{abstract}
Papillary mesothelioma is a well differentiated neoplasm arising from pelvic peritoneum of females in a wide age range. A typical morphological appearance is papillary structures with fibro vascular cores. We present a case of a 46-year-old female with a mass in left peritoneal cavity involving the left fallopian tube which was excised and reported as a papillary mesothelioma.
\end{abstract}

Key Words: Mesothelioma, Fallopian tube, Peritoneum, Adnexa

\section{INTRODUCTION}

Adnexal mass in a perimenopausal woman has to be evaluated for suspected malignancy. Imaging and biochemical work up must be done thoroughly prior to surgical intervention so that optimal surgical excision can be done. However some adnexal masses cannot be characterized well on imaging and even at laparotomy and only histopathology can guide at the end. One such case of papillary mesothelioma involving the fallopian tube is presented here.

\section{Case presentation}

A 46-year-old lady, mother of five children was referred to a tertiary care hospital for evaluation of irregular vaginal bleeding. Her irregular periods were treated with progestogens. Apart from history of three caesarean sections in the past there was no significant past medical or surgical history. On examination she was found to be overweight with a body mass index of 30 and unremarkable general examination. Breasts and thyroid were normal. Abdominal examination revealed a pfannensteil caesarean scar and a small para umbilical hernia. External genitalia and cervix were normal. A Pap smear was performed. On bimanual examination an illdefined mass was palpated in the left adnexa. Transvaginal ultrasonography showed a normal uterus and ovaries with an ill-defined solid mass in the left adnexa close to the uterus. Images of the computerized tomography and magnetic resonance imaging of the pelvis revealed a normal uterus and ovaries with a heterogeneous lobulated vascular mass in the left adnexa with no obvious features of malignancy, measuring about $7 \mathrm{~cm}$. There was no ascites and no pelvic or para-aortic lymphadenopathy. A broad ligament fibroid and a solid ovarian mass were considered as differential diagnoses.

Results of routine haemogram, renal function tests, liver function tests, Pap smear of the cervix were normal. CA 125 was $77 \mathrm{iu}$, alpha fetoprotein $(\alpha \mathrm{FP})$ and beta human chorionic gonadotropin ( $\beta \mathrm{HCG}$ ) were normal. The differential diagnosis considered solid adnexal tumor and broad ligament

\footnotetext{
*Correspondence: Vaidyanathan Gowri, Associate Professor; Email: gowrie61@ hotmail.com; Address: OBGYN department, College of Medicine and health Sciences, PO BOX 35, Postal code 123, Sultan Qaboos University, Muscat, Oman.
} 
fibroid just prior to laparotomy. The images were discussed with radiologist and they felt there was no suggestion of malignancy in the mass or otherwise.

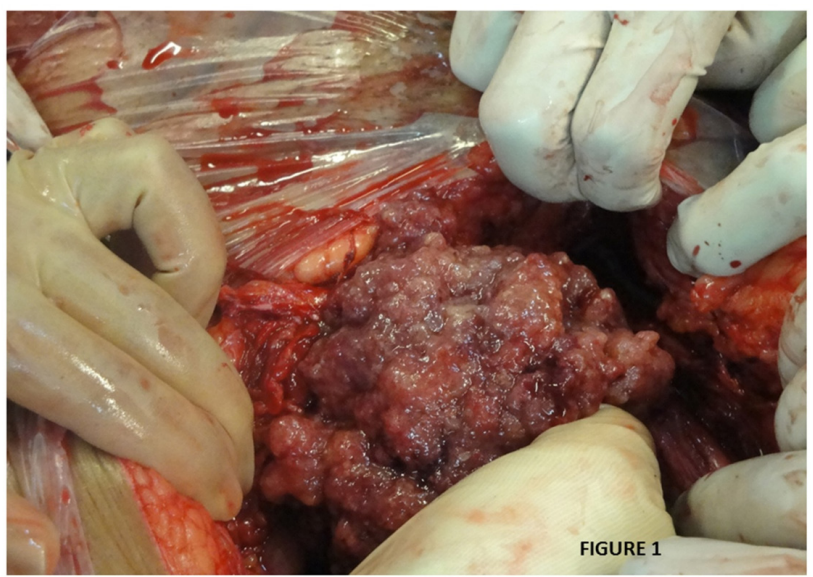

Figure 1. The photograph of the tumor while the patient is being operated

A midline laparotomy was performed. The findings at laparotomy were: unicornuate uterus (well developed right horn and rudimentary left horn); normal looking both ovaries and fallopian tubes. There was straw colored ascitic fluid of about $200 \mathrm{ml}$. A fleshy mass, trophoblast like, pinkish, irregular, soft to firm attached to the left fallopian tube about $6 \mathrm{~cm}$ in diameter was seen on opening the abdomen (see Figure 1). There were no peritoneal deposits; no pelvic or para aortic lymphadenopathy. Liver, stomach, bowels and appendix were normal. Total hysterectomy with bilateral salpingo-oophorectomy was performed. The surgical specimen was sent for histopathological examination. The spongy mass sent from the peritoneum showed a papillary neoplasm with fibro-vascular cores (see Figure 2A and 2B). These were lined by cuboidal cells with minimum nuclear atypia and pleomorphism. There were focal areas of necrosis. Tumor cells were positive for WT1, Calretinin and focally for Desmin (see Figure 2C and 2D). Morphology and immunohistochemical profile raised differential diagnosis of serous papillary neoplasm and papillary mesothelioma. The slides were sent to an expertized pathologist for the second opinion. The final diagnosis was papillary mesothelioma. Her appointment after surgery was six months later and she remained well being.

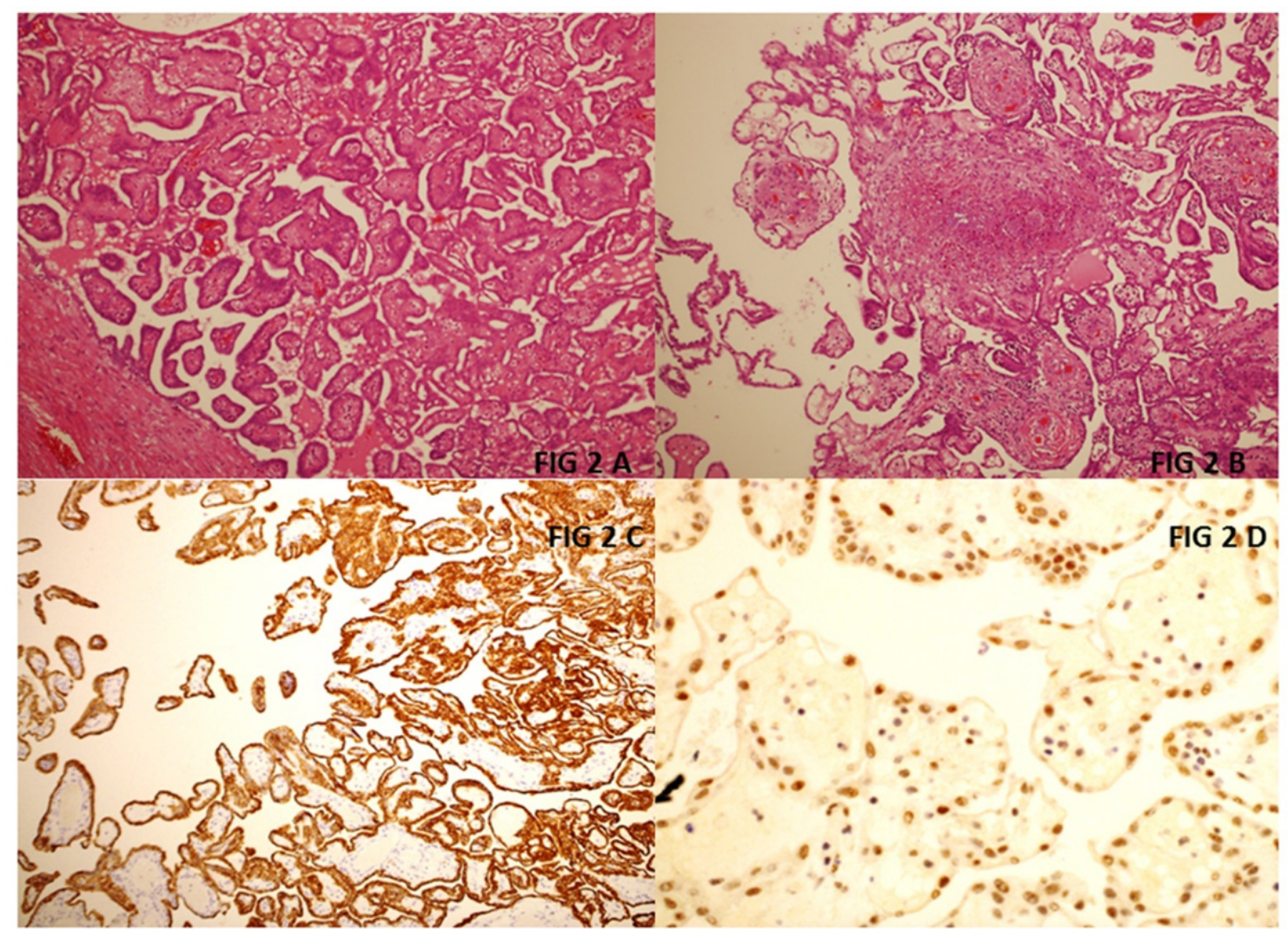

Figure 2. A) $\mathrm{H}$ and $\mathrm{E}$ section at $4 \times$ magnification showing a papillary neoplasm with fibro vascular cores; B) $\mathrm{H}$ and $\mathrm{E}$ section showing a papillary neoplasm lined by cuboidal type epithelial cells with areas of necrosis and C) Wt 1 immunohistochemical stain positive in tumor cells; D) Desmin immunohistochemical stain diffusely positive in tumor cells. 


\section{Discussion}

Papillary mesothelioma is a rare neoplasm with excellent prognosis and only less than a 100 cases have been reported. ${ }^{[1,2]}$ Thoracic mesotheliomas are associated with asbestos exposure however peritoneal mesotheliomas do not have a strong correlation with asbestos exposure. Environmental factors and germ line mutations have also have been described in the pathogenesis. ${ }^{[3,4]}$

Well differentiated papillary mesothelioma is considered a borderline malignant potential tumor and follows an indolent clinical course, however, the disease may recur locally following resection, and occasionally may remotely transform into malignant mesothelioma. ${ }^{[5]}$ The treatment of choice should be complete surgical removal with no macroscopic disease left behind. ${ }^{[6]}$ The common immunohistochemical profile for mesothelioma is expression of calretinin, cytokeratin 5/6, D2-40, and WT1. The Ki67 index is always low $<1 \%$. Epithelial markers are reported negative in these tumors. ${ }^{[7]}$

In a series of 26 cases described by Mapilca et al. of well differentiated papillary mesothelioma of the female peritoneum only one involved the fallopian tube. They reported only one case of recurrence in a mean follow up time of 47.5 months and no woman died of this disease. ${ }^{[6]}$ Rabban et al. described the pattern and topography of 100 non gynecologic cancers that metastasized to the fallopian tubes, a potential mimic of tubal high-grade serous carcinoma and benign tubal mucinous metaplasia or nonmucinous hyperplasia. Most tumors were adenocarcinoma (87\%), and the remainder included lymphomas, neuroendocrine tumors and mesotheliomas. ${ }^{[8]}$ Though mesothelioma involving the fallopian tube is a rare entity and usually a benign caution should be used in applying the designation "well-differentiated papillary mesothelioma" and multifocal lesions must be thoroughly examined histologically because of potential overlapping features with malignant mesothelioma. ${ }^{[9]}$

Mainstay of treatment is removing the tumor as far as possible and in cases where this cannot be achieved intra peritoneal chemotherapy may help. Good prognostic indicators in our case included age less than 50, female gender localized disease and no lymph node metastases. ${ }^{[10]}$ Our patient met all the criteria, and hence was treated with complete cytoreduction only. The 5-year survival with such treatment is around $90 \%$. Despite complete resection, the patient needs long-tern surveillance.

\section{Conclusion}

Papillary mesothelioma is a rare tumor with an excellent prognosis. The case we present here posed a diagnostic challenge because of its unusual presentation. Mesothelioma does not invade underlying structures but this one did. This case had all the good prognostic features at the time of both diagnosis and surgery. Cytoreductive was the treatment of choice.

\section{CONFlicts OF INTEREST Disclosure}

The authors declare that there is no conflict of interest statement.

\section{REFERENCES}

[1] Kindler HL. Peritoenal mesothelioma: The site of origin matters. ASCO Educational Book. 2013: 182-8.

[2] Clarke JM, Helft P. Long-term survival of a woman with a well differentiated papillary mesothelioma of the peritoneum: a case report and review of the literature. J Med Case Rep. 2010; 4: 346. PMid:21029480. https://doi.org/10.1186/1752-1947-4-3 46

[3] Galateau-Salle F, Vignaud JM, Burke L, et al. Well differentiated papillary mesothelioma of the pleura: a series of 24 cases. Am. J Surg Pathol. 2004; 28; 534-40. PMid:15087673. https: //doi.org/10.1097/00000478-200404000-00013

[4] Ribeiro C, Campelos S, Moura CS, et al. Well-differentiated papillary mesothelioma: clustering in a Portuguese family with a germline BAP1 mutation. Ann Oncol. 2013; 24: 2147-50. PMid:23585512. https://doi.org/10.1093/annonc/mdt135

[5] Lee YK, Jun HJ, Nahm JH, et al. Therapeutic Strategies for Welldifferentiated Papillary Mesothelioma of the Peritoneum. Jpn J Clin Oncol. 2013; 43(10): 996-1003. PMid:23964112. https: //doi.org/10.1093/jjco/hyt117
[6] Malpica A, Sant'Ambrogio S, Deavers MT, et al. Well-differentiated papillary mesothelioma of the female peritoneum: aclinicopathologic study of 26 cases. Am. J. Surg. Pathol. 2012; 36: 117-27. PMid:22024662. https://doi.org/10.1097/PAS.0b013e3182 $354 a 79$

[7] Foyle A, Al-Jabi M, McCaughey WT. Papillary peritoneal tumors in women. Am. J. Surg. Pathol. 1981; 5: 241-9. PMid:7235119. https://doi.org/10.1097/00000478-198104000-00004

[8] Rabban JT, Vohra P, Zaloudek CJ. Nongynecologic metastases to fallopian tube mucosa: a potential mimic of tubal high-grade serous carcinoma and benign tubal mucinous metaplasia or nonmucinous hyperplasia. Am J Surg Pathol. 2015 Jan; 39(1): 35-51. PMid:25025442. https://doi.org/10.1097/PAS.0000000000000293

[9] Baker PM, Clement PB, Young RH. Selected Topics in Peritoneal Pathology. International Journal of Gynecological Pathology. 2014; 33(4): 393-401. PMid:24901399. https ://doi .org/10.1097/PG P. 0000000000000146

[10] Yan TD, Deraco M, Elias D, et al. A novel tumor-node-metastases (TNM) staging system of diffuse malignant peritoneal mesothelioma using outcome analysis of a multi-institutional database. Cancer 2011; 117: 1855-63. PMid:21509762. https://doi.org/10.100 $2 /$ cncr. 25640 